\title{
MULTIPLE JOB HOLDING IN NEW ZEALAND: A GROWING PRESENCE IN NEW ZEALAND'S LABOUR MARKETS, 20-YEAR TRENDS
}

\author{
James Baines \\ Taylor Baines and Associates \\ Jamie Newell \\ Monitoring Evaluation Research Associates
}

\begin{abstract}
This paper provides an analysis of trends in multiple job holding over the 20 year period from 1981 to $2001 . \quad$ The analysis builds on the initial statistical profile of the incidence of multiple job holding in New Zealand, based on the 2001 Census of Population and Dwellings. The longitudinal analysis utilises a new statistical library to obtain data on work over time. The analysis places the growth in multiple job holding and other forms of non-standard work in the context of the nation's labour markets, as they went through the transformations of the mid-1980s, the recession of the late 1980s, and the subsequent economic recovery during the 1990s. The paper also reports some preliminary analysis of multiple job holding data from the Time Use Survey, which is unique in New Zealand statistics for the fact that it identifies the occupations involved in each of the jobs. This research programme is on going.
\end{abstract}

\section{Introduction}

\section{The Research Programme - Objectives and Outline}

The purpose of this research programme $e^{(1)}$ is to provide knowledge about the way individuals, families and communities are adapting to social and economic change through multiple job holding - working in more than one job contemporaneously ${ }^{(2)}$. The programme complements and extends previous research into the characteristics of work in natural resource sectors to provide comprehensive information on multiple job holding across a range of sectors.

The research began in 2001 and is broken into two main objectives. The work in these objectives is currently focussed on:

- developing a census-based time series of data on multiple job holding, and comparing census data sets with data on multiple job holding from other statistical surveys such as the Time Use Survey and the Household Labour Force Survey.

- $\quad$ identifying the factors which encourage or inhibit multiple job holding, and determining the impacts of multiple job holding on individuals, families and communities through a series of 180 in-depth interviews.

The research findings will contribute to the outcomes sought by FRST in the "Family and Community Wellbeing" portfolio. Various agencies and groups working in labour market policy and facilitation, or with an interest in the social outcomes of labour market policy have expressed interest in the findings so far - the Ministry of Social Development, the Ministry of Women's Affairs, the Community Employment Group of the Dept of
Labour, as well as other research teams such as the Labour Market Dynamics Group at Massey University's Albany campus.

\section{Multiple Job Holding and Flexible Work}

The phenomenon of workers having more than one job at a time - what we refer to here as 'multiple job holding' is associated with the casualisation of employment and a trend to more flexible work patterns in Western societies. There is an apparent long-term trend to "non-standard" employment for individuals, employment that is not fulltime for a basic 37.5 hour week. In New Zealand, the growth in flexible work practices is attributed to the processes of globalisation and decentralised bargaining (McLaren, 2001). Results presented later in this paper confirm the extent of this long-term trend in the New Zealand labour force.

Motivations behind the trend to multiple job holding vary for employers and workers. Employers enjoy the economic and business management benefits of more flexible employment arrangements. Employees are motivated either by the need to build a sufficient level of individual or household income, or by aspects of work satisfaction or professional development. In particular, low-skill workers with low incomes have several jobs to pay for household necessities. However, multiple job holding also includes professional workers such as health professionals. In addition to building their income, they are motivated by the benefits for their personal and family lives which derive from more flexible work (Chapman, 2000).

Multiple job holding has been widely used by farm families for some time to maintain or supplement farm income (Taylor and McCrostie Little, 1995). It is also evident in other parts of the rural economy as with meat 
processing workers (Shirley, et al. 2001), and specifically-skilled, casual, mobile, workers (e.g. shearers and ski instructors) having a portfolio of jobs in order to achieve year-round work, sometimes even across international locations (Hunt, 1996).

\section{Approach to Investigations}

\section{The Sequence of Investigations}

In terms of the quantitative analysis being carried out in this research programme, the work began by examining which demographic variables are more important for explaining differences in the incidence of multiple job holding in various parts of the labour market. That work led on to preparing a snap-shot statistical profile of multiple job holding across the New Zealand economy, based on the 2001 Census of Population and Dwellings (Baines \& Newell, 2003), which was presented to the $10^{\text {th }}$ LEW conference in November 2002 (Baines et al. 2002).

Since the initial statistical profile was completed, work has focussed on preparing a time series of data on multiple job holding trends from the five official censi which span the period 1981 to 2001 .

\section{A Common Analytical Framework}

Since the focus has turned towards an analysis of trends and dynamic change in labour markets over time, this investigation also attempts to present the findings on multiple job holding in the broader (statistical) context of labour market change. This analytical framework has taken an explicit cue from the work of the Dept of Labour (2003, p.7). This conceptual overview (Figure 1) depicts the relationships between 'sets' of people in the New Zealand population and in the New Zealand labour market. For example, as people reach working age, they become eligible to enter the labour force. However, not everyone who is eligible wants to be in the labour force, such as retired people, or those who wish to become involved in full-time education. Parents who chose to stay at home with childcare or house keeping responsibilities are not generally included in the labour force either, although in some cases, unpaid work for farm or family businesses may blur this distinction. Not everyone who wants to be in the labour force is employed. But recent statistical practice has given rise to an intermediate group, cuphemistically referred to as 'marginally attached' to the labour force. These are people in the working-age population, but not the labour force, who are either available, but not actively seeking work, or are actively seeking, but not available for work (e.g. someone looking for a job to start when their study finishes). Finally, a net increase in the population is affected by births, deaths and migration. Figure 1 shows both graphically and quantitatively how people move from one situation to another.

For our purposes, we can add to this conceptual diagram by disaggregating the 'employed' set within the labour force into standard and non-standard workers (Figure 2) and also by further disaggregating the set of non-standard workers into the various categories which reflect a more differentiated labour market (Spoonley and Davidson, 2004, pp.25-29). Non-standard workers include part-time workers, casual workers, temporary workers, the ownaccount self-employed, and those working in more than one job simultaneously (multiple job holders).

This disaggregation of the different categories of employment relationships serves two main purposes. Firstly, it provides a fuller and more realistic description of the labour market. New Zealand statistics have for some time recognised the situation of the own-account self-employed workers. Since the 1980 s, the statistics on part-time work have become more rigorously differentiated. However, there are no New Zealand statistics on casual or temporary work, and the statistics on multiple job holding have not evolved beyond the point of recognising that the phenomenon exists. That is to say, the statistics record people with more than one job, but do not record how many jobs; nor are detailed statistics collected on the characteristics of all the jobs, as they are for the designated main job. Secondly, disaggregating the categories of standard and nonstandard work may help us to gain a better understanding of the mechanisms or journeys by which people move from one situation to another - from not being in the labour force to being in the labour force; from being unemployed to being employed.

In due course, this common analytical framework will facilitate comparison of data and trends between the census-based analysis carried out in this research programme and the analysis carried out by the Dept of Labour, based on the Household Labour Force Survey. The common framework has also been used for the comparison of data from the Time Use Survey.

\section{Statistical Data Sources}

In the Census, the question is asked "In the 7 days that ended on ..... did you have one job or more than one job?" While the Census data have some real strengths, they also have some weaknesses. The most obvious shortcoming is that the official census contains no data at all on the nature of a person's second job. For example, there is no information on whether the second job is in the same occupational or industry grouping or in a different grouping. In fact, there are reasons to suspect that census responses classifying some aspects of work-related questions may reflect a degree of respondent confusion and some inconsistency in responses. Other weaknesses were discussed in the Working Paper describing the initial statistical profile (Baines \& Newell, 2003, pp.2728). These weaknesses, to do with census responses varying perceptions of what constitutes 'work'; confusion between the concepts of 'job' and 'occupation'; reluctance to report ${ }^{(3)}$ on their true job status in order to protect a beneficiary status - all point to the possibility of significant under reporting of multiple job holding in the census, a point we will re-visit in the discussion section. Nevertheless, because the data come from a full census they allow a far more detailed analysis than any other statistical data set in the country. This can be seen from the information presented in Table 1. 
Figure 1: New Zealand's Labour Market within the Context of Working-Age Population and Total Population

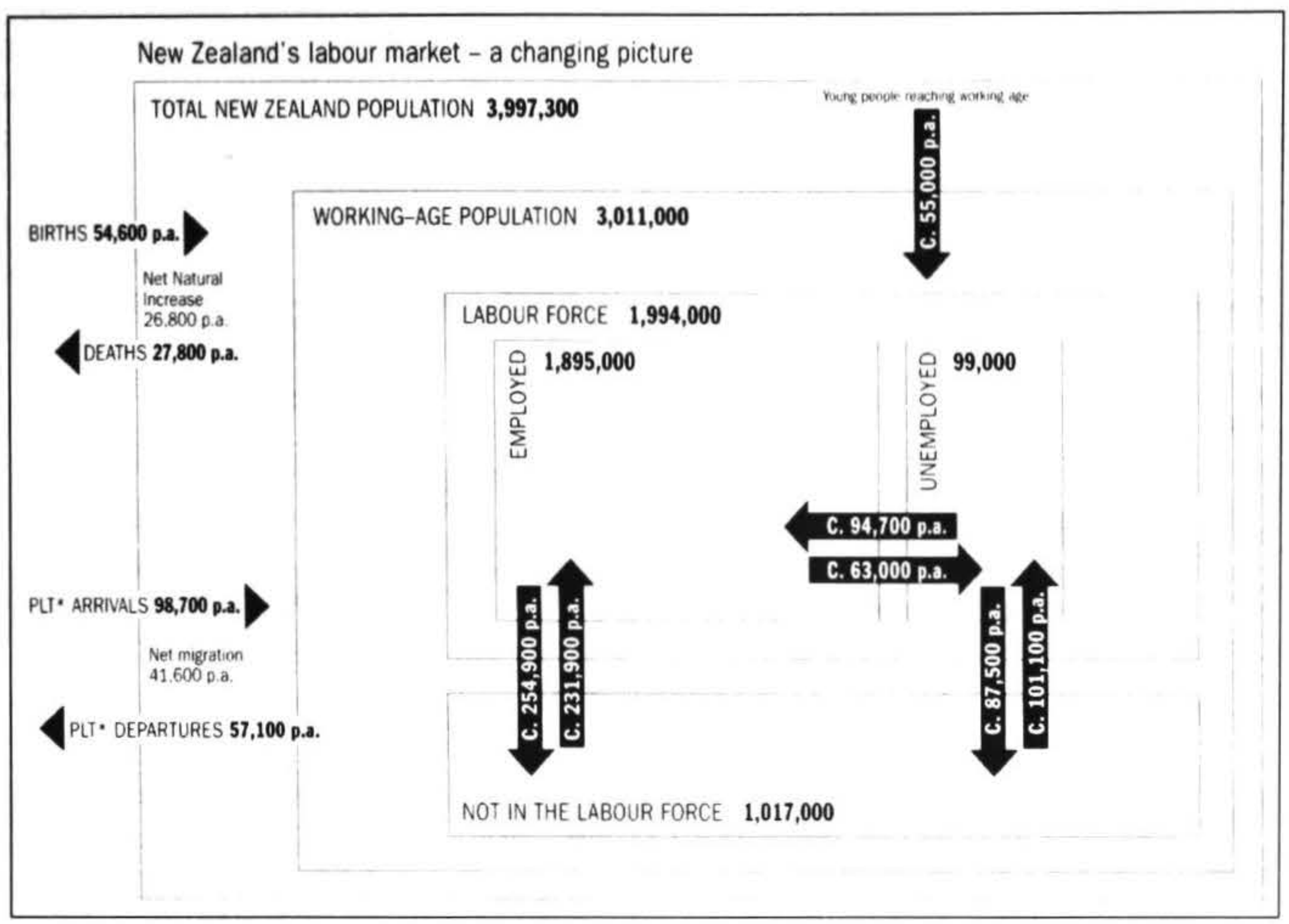

Source: Dept of Labour, 2003. Work Trends - How work is changing in New Zealand produced by the Department's Future of Work programme

Figure 2: New Zealand's Labour Market Disaggregated

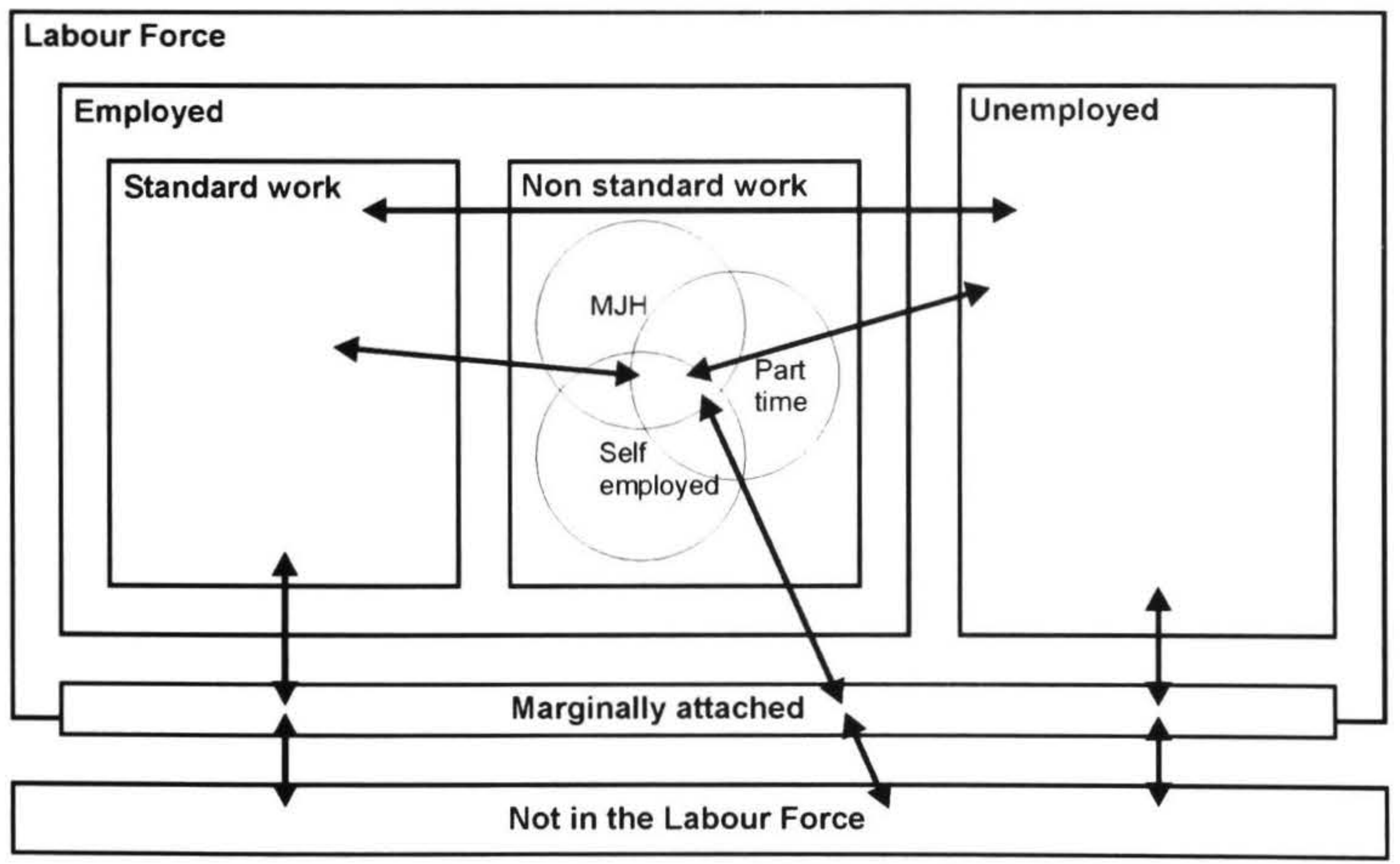


Table 1: Comparison of Census and Survey Sample Sizes

\begin{tabular}{|c|c|c|c|}
\hline Census/survey & Timing & Sample size & Sampling error ${ }^{(4)}$ \\
\hline $\begin{array}{l}2001 \text { Census of Population and } \\
\text { Dwellings }\end{array}$ & $\begin{array}{l}\text { Five-yearly intervals; most recently in } \\
\text { March } 2001\end{array}$ & $\begin{array}{l}1,727,271, \text { aged } 15 \\
\text { years and above }\end{array}$ & Essentially zero \\
\hline $\begin{array}{l}\text { Household Labour Force } \\
\text { Survey }\end{array}$ & Quarterly since 1985 & $\begin{array}{l}30,000 \text { individuals in } \\
16,000 \text { households }\end{array}$ & \\
\hline Household Economic Survey & $\begin{array}{l}\text { Annually 1973-98; thereafter every three } \\
\text { years; most recently } 2001\end{array}$ & 3,000 households & $\pm 2.4 \%$ \\
\hline Time Use Survey ${ }^{(5)}$ & Once only so far: July 1998 - June 1999 & $\sim 8,500$ individuals & $\pm 1.4 \%$ \\
\hline
\end{tabular}

Assembling time series data sets from five different censi over twenty years presents its own unique challenges for producing a harmonised series. These challenges include changing practices in census data coding and data entry ${ }^{(6)}$, changes in classification system (particularly, for example, in occupational classifications $\left.{ }^{(7)}\right)$; and changes in the form of the question (particularly regarding ethnicity $^{(8)}$ and unemployment status ${ }^{(9)}$ ).

\section{Results}

Results from the statistical analysis are presented in four sections. Firstly we present 20-year trends on macrolevel variables associated with New Zealand's labour market from 1981 to 2001. Secondly we provide a summary of the long-term trends in various aspects of non-standard work, to the extent permissible by census statistics. This is followed by a more detailed analysis of trends in multiple job holding in New Zealand. Finally, corresponding data from the one-off Time Use Survey (1998-99) is presented for comparative purposes.

\section{Macro-level Trends}

The period from 1981 to 2001 was a period of major economic change and upheaval in labour markets. At the beginning of the period, New Zealand was a relatively closed economy characterised by high inflation, restrictive sectoral protection and highly structured labour relations. The period witnessed all the restructuring that occurred as a result of the government-driven reforms after 1984, the recession from 1987, and the resurgence from 1990 onwards.

When examining labour market change through the lenses of the 5-yearly census, it is important to remember that each census simply catalogues relative change over the preceding 5-year period; the 5-yearly intervals themselves are arbitrary in that regard, and the actual timing of peaks and troughs in the trends shown may not be accurately depicted. Nevertheless, the time series analysis can reveal aspects of ctumulative and relative change that may be of interest. By way of example, the trends for working-age population, labour force, total employed and unemployment level over this twenty-year period are presented in Figures 3-5. Figure 3 shows trends in the absolute numbers, while in Figures 4 and 5 the results are expressed as indices, where 1981 values correspond to an Index Value of Unity (1.0).

These trends in absolute values do not make it easy to see relative changes in the variables; hence the use of indices of change in subsequent figures. Figure 4 focuses on relative change in working -age population, total labour force and total numbers employed, since the scale of changes is similar in order of magnitude. Figure 5 adds changes in total unemployment levels into the overall picture.

These comparative indices reveal contrasting trends between the working-age population which, not surprisingly, continued to grow unabated throughout the whole period, and the total labour force and total number of people actually in jobs, which went through severe dislocation during the 1980s but have shown commensurate recovery during the 1990s.

Figure 5 shows how levels of unemployment have changed much more significantly during this period than other aspects of the labour market, and how unemployment levels are influenced by trends in job creation and trends in numbers of people of working age (eligible to be in the labour force) and trends in the desire to participate in the labour force. For example, between 1981 and 1986, job creation increased marginally faster than the working-age population, but the numbers wishing to participate in the labour force grew even faster, reflected in the rapid increase in unemployment numbers during this time. Even though the uncertainties of the late 1980s dampened expectations about labour force participation, the substantial loss of job numbers saw unemployment numbers continuing to rise rapidly. The rapid growth in job numbers created in the early 1990 s had some impact on unemployment numbers, but the more buoyant circumstances also encouraged greater expectations to participate so that unemployment numbers have persisted in the face of a working-age population that continues to grow substantially.

A similar analysis can be carried out on sub-populations or sub-sections of the labour market, differentiating the sexes, ethnicities, regions, age groups, and so on. By way of example, a comparison between women and men in New Zealand is shown below. The same can easily be done by ethnicity, or age, and indeed by combinations of these variables. 
Figure 3: Total NZ Labour Market - Absolute Values

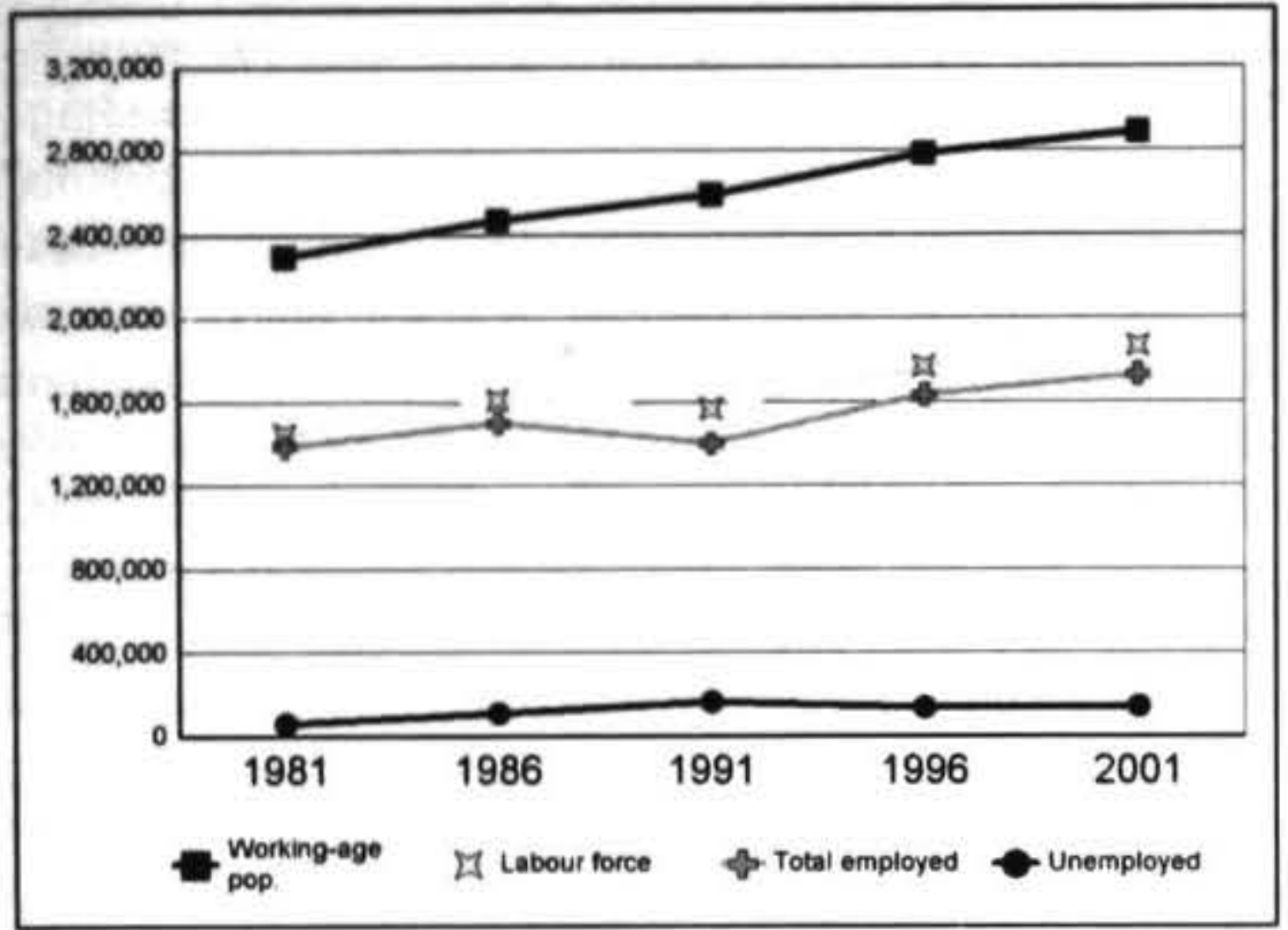

Figure 4: Total NZ Labour Market - Indices of Relative and Cumulative Change

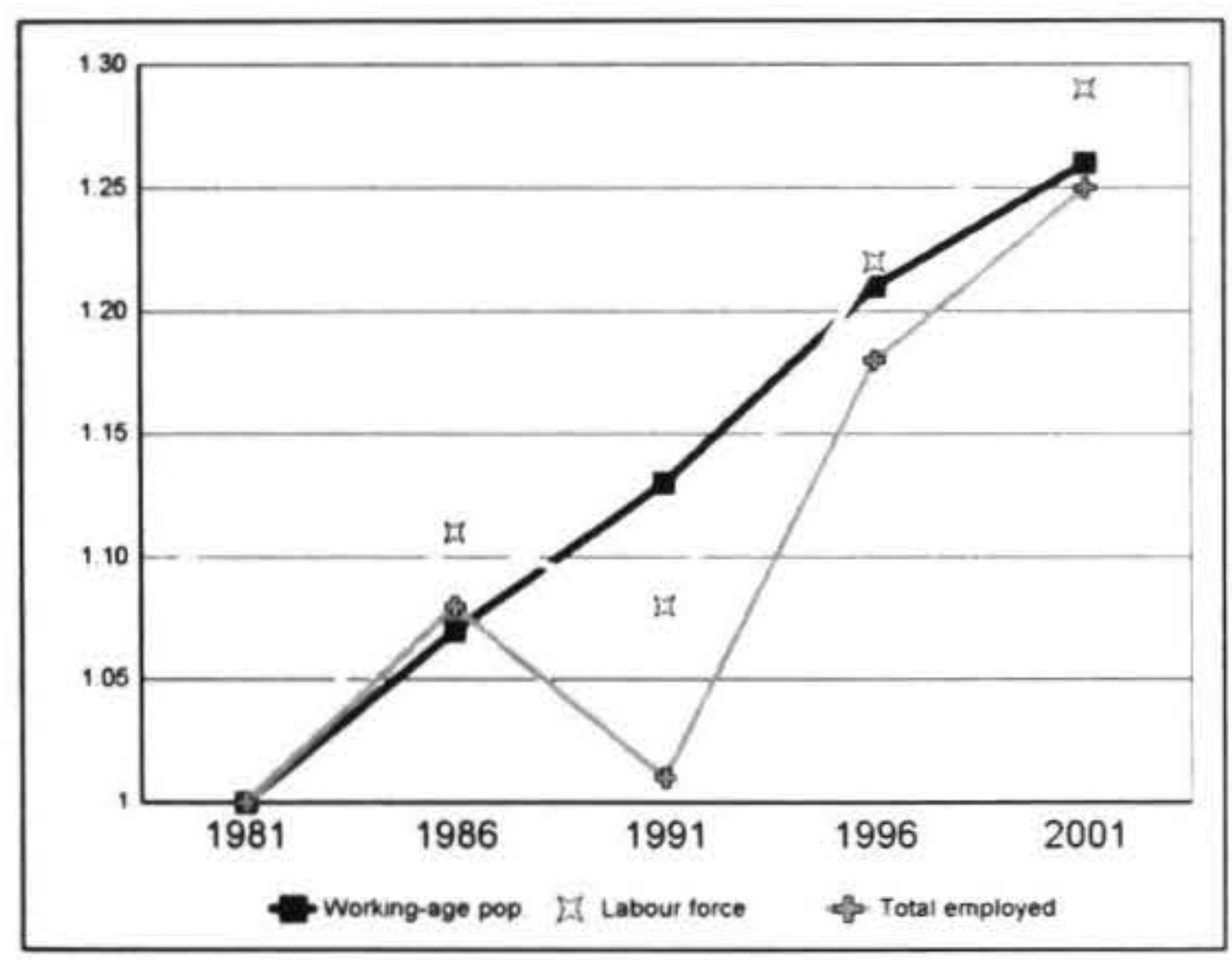

Figure 5: Total NZ Labour Market, including Unemployment - Indices of Relative and Cumulative Change

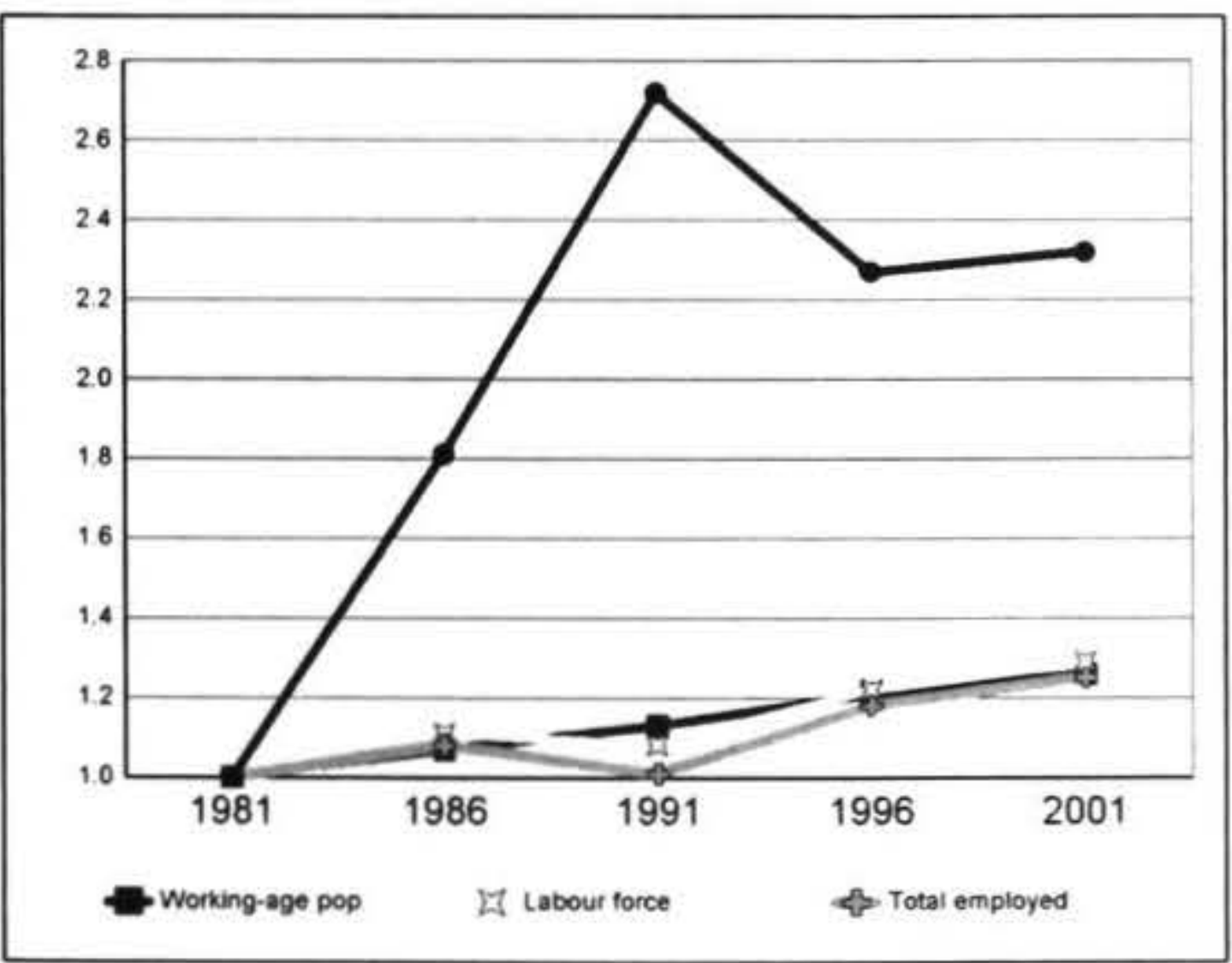

Figure 6: Index of Working-Age Population: Women vs Men

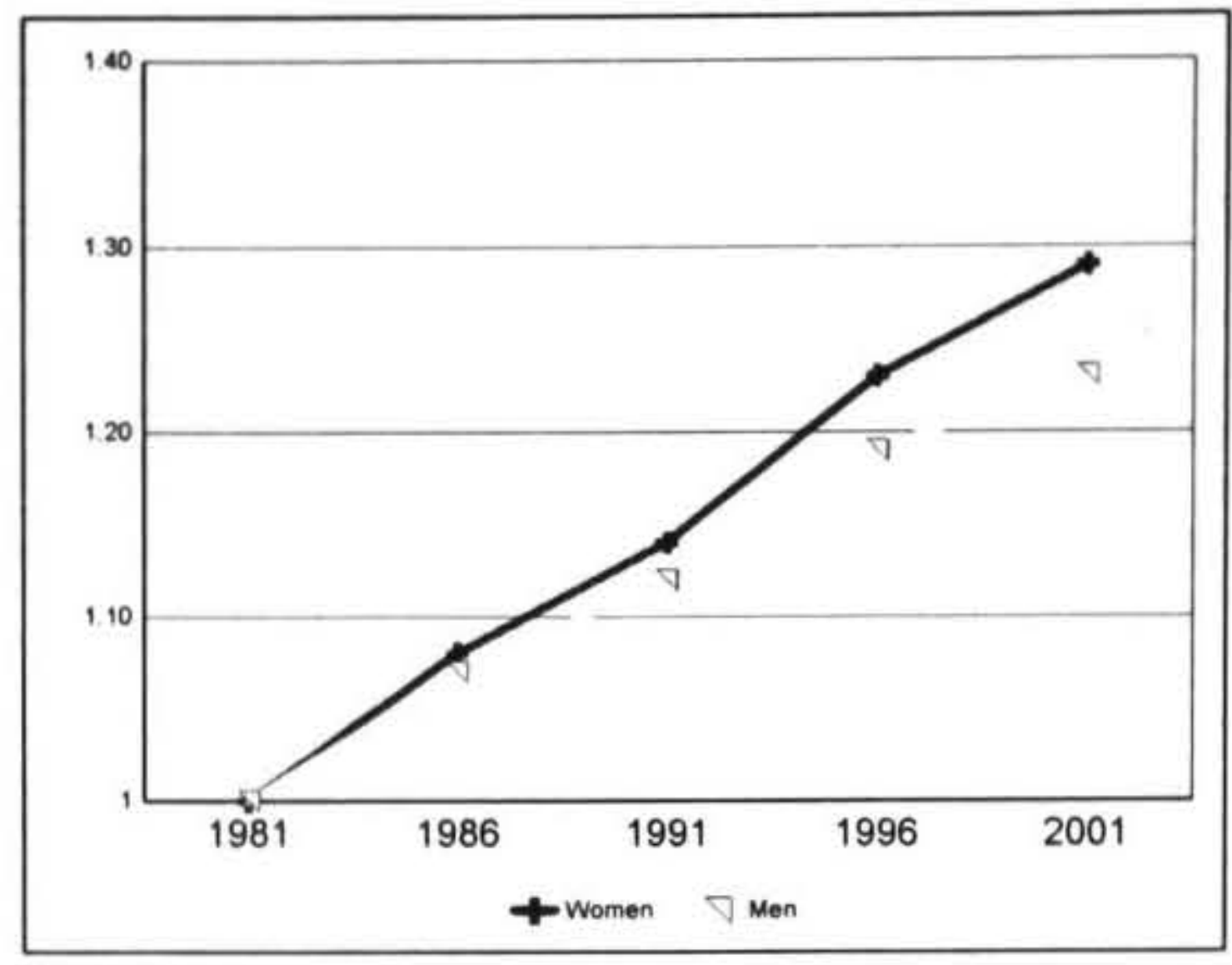

Figure 7: Index of Total Employed: Women vs Men

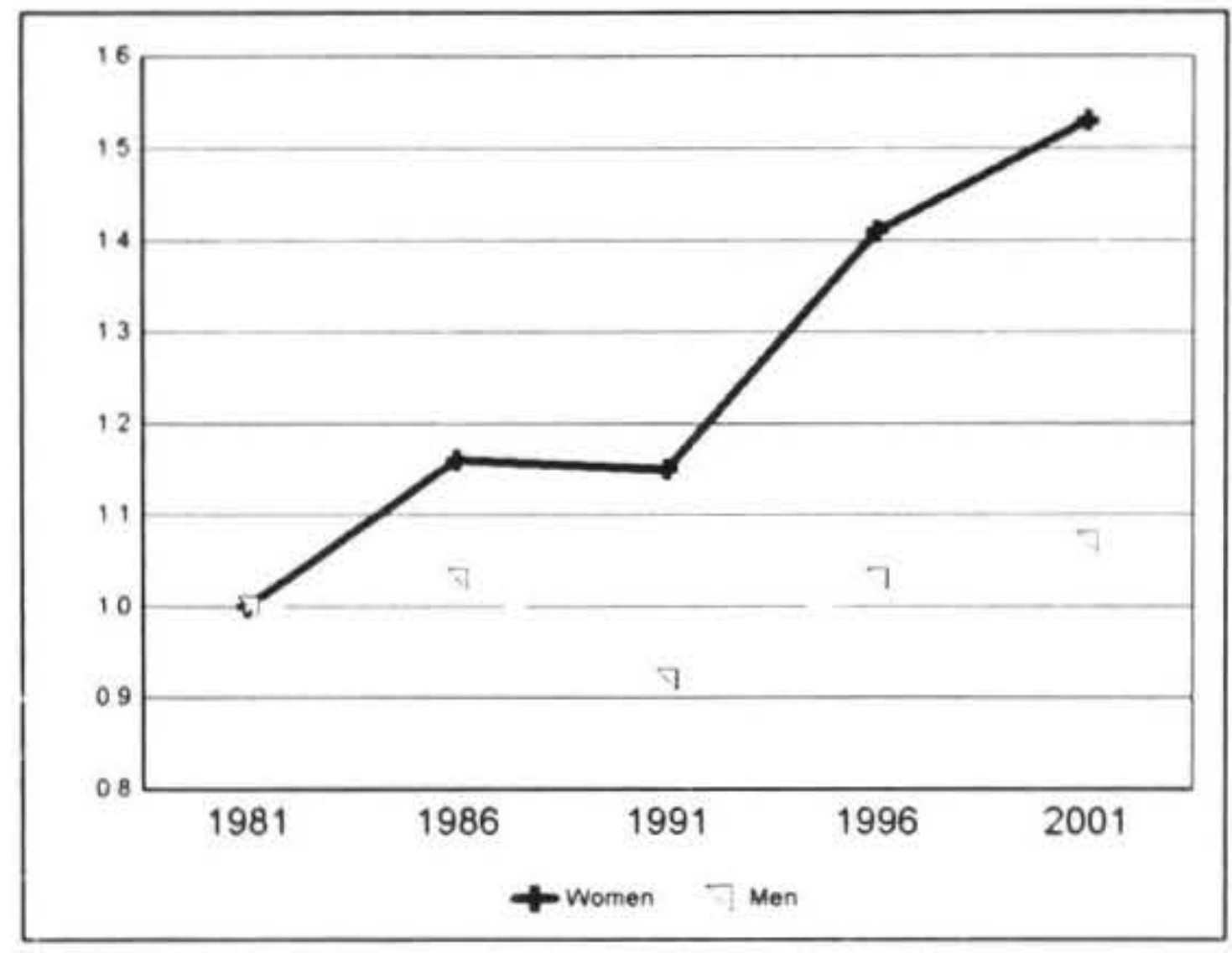

Figure 8: Index of Unemployment: Women vs Men

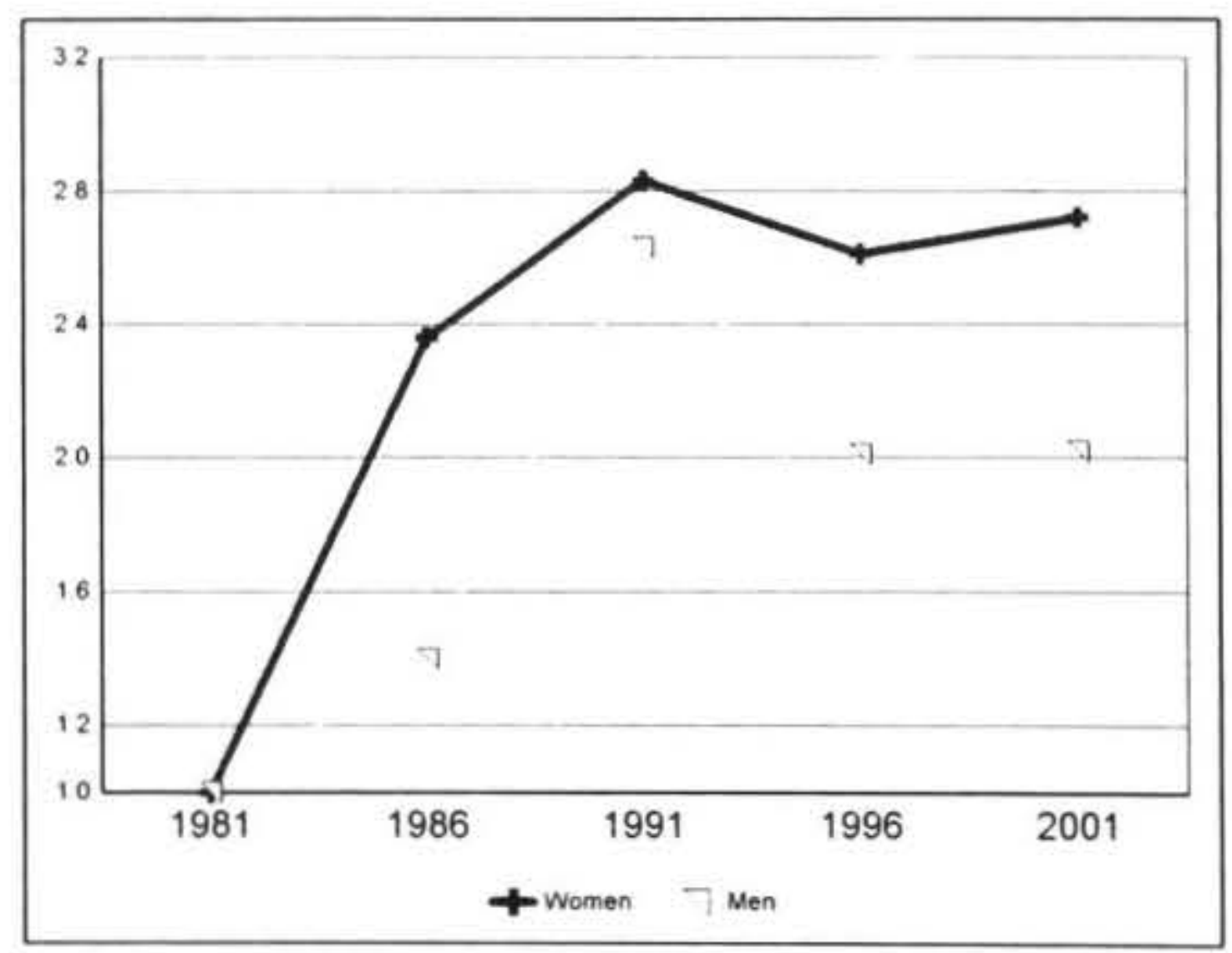


The female component of the working-age population has consistently grown faster than the male component over the past 20 years, increasing by $29 \%$ compared with $23 \%$ for males.

The restructuring and recession in the second half of the 1980s hit men harder than women, in terms of those who already had jobs. In 1981, men held $62 \%$ of the jobs. By 2001 , this proportion had fallen to $53 \%$. Men's labour force participation rates declined from almost $80 \%$ in 1981 to plateau at around $71 \%$ since 1991 . In contrast, women's labour force participation rate (formal economy) was recorded as $47 \%$ in 1981 and was still rising in 2001 at $58 \%$.

The changes in the labour market affected women as well, but in a different sequence. Rising expectations of labour force participation amongst women in the early 1980s meant that women's unemployment increased much more rapidly than mens. However, by the time these changes in labour market conditions had played out, men had caught up. Women's unemployment - in absolute terms appears not to have abated nearly as much as men's unemployment during the 1990s.

Figure 9: Industry Sector Trends - Indices of Change $(1981=1.00)$

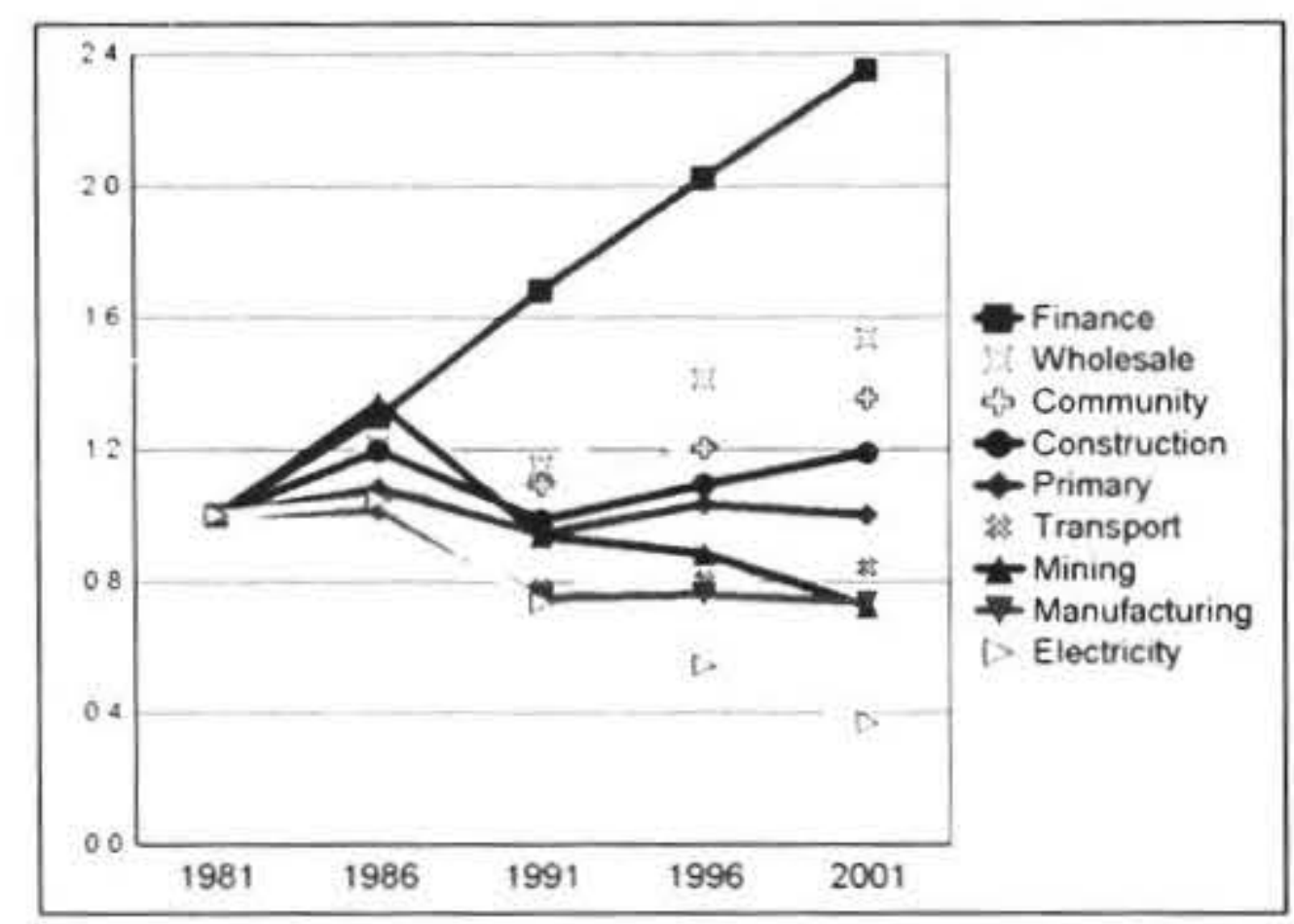

Figure 10: Industry Sector Trends - Inter-censal Change in Workforce Numbers

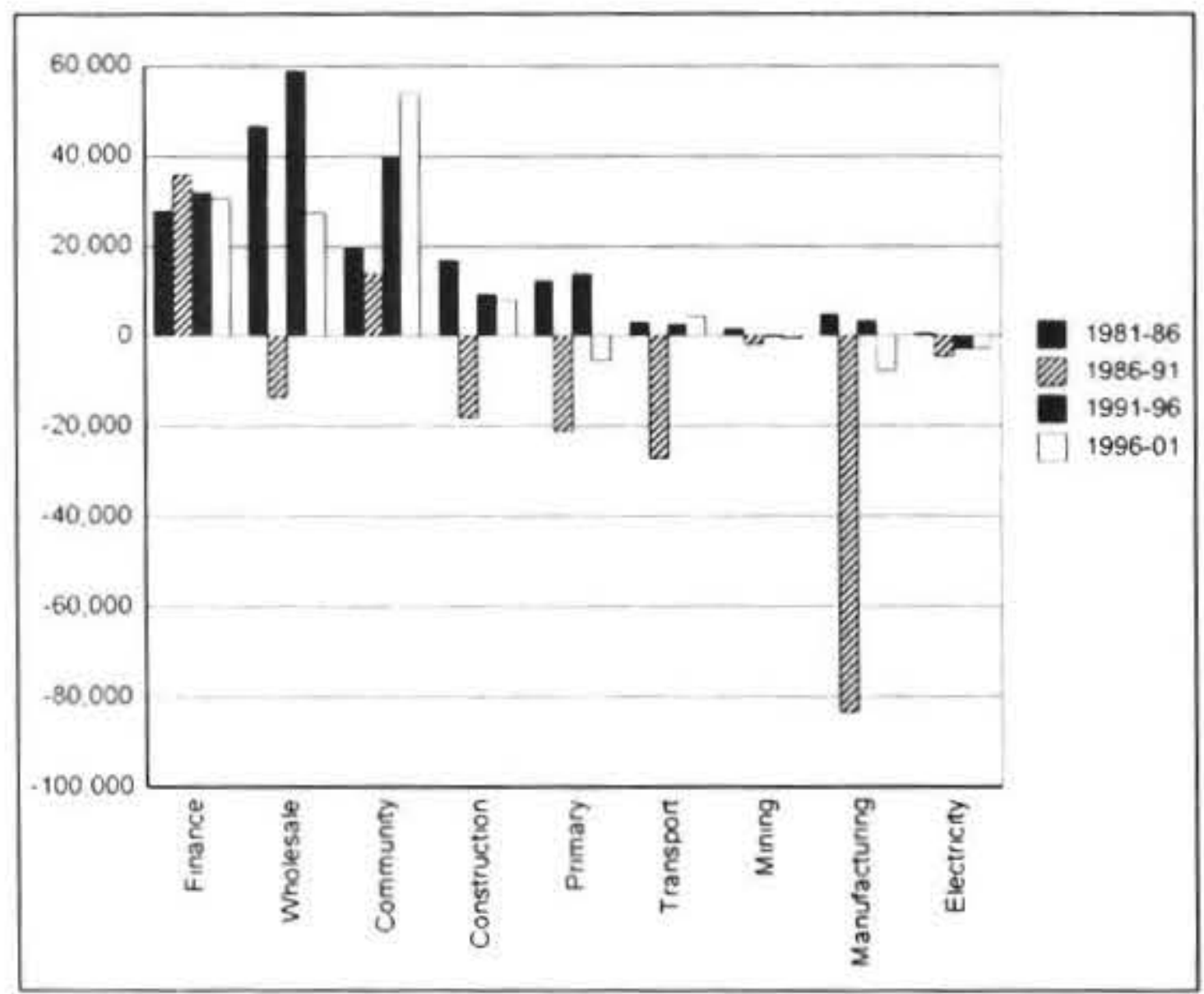

Another aspect of major change during this period which can be analysed in the census time series is the relative fortunes of industry sectors. As noted by the Dept of
Labour in its analysis of work trends (DoL, 2003, pp.1213), the experience of industry sectors has been extremely diverse (Figure 9). Services sectors have led the growth in workforce numbers, with financial services standing out as having had the highest and steadiest growth throughout the last two decades. The financial services and community services sectors are the only sectors which appear to have ridden through the turbulence of the 1980s reforms and recession without overall loss of momentum in workforce growth. The wholesale and trade sector was the other main contributor to job growth during the 1990s. The primary industries sector has experienced much change and mixed fortunes, but overall rural workforce numbers in this sector ended up in 2001 in much the same numerical situation as they were two decades previously.

Major workforce loss occurred in manufacturing, mining and the electricity utilities sectors. Growth in the mining sector workforce in the 1981-86 period (the highest of all sectors during this period) reflects the last years of 'think big' developments (coal and oil\& natural gas), while the sharp decline in the electricity sector workforce reflects the extensive restructuring that accompanied corporatisation and privatisation in this sector. This pattern of change is confirmed by the data on absolute job numbers shown in Figure 10.

A similar analysis can be done by region, age band, ethnicity or sex.

These data confirm the dominant role played by the service sectors in overall job growth during the past two decades. They also confirm the late 1980 s as the period of greatest job losses. Net job losses since 1991 have been very small.

\section{Long-term Trends in Non-standard Work}

Spoonley and Davidson (2004) provided a reference point against which to discuss the concept of non-standard work when they wrote (p.25) "By the twentieth century, employment typically occupied male breadwinners who journeyed to their employers place of work. Wage settlements in mid-twentieth century New Zealand were required to provide a 'living wage', which was defined as a wage sufficient to provide adequate income for a wife and three children." They went on to observe (p.26) that "If standard employment has been the benchmark of labour relations and policy in the post World War II period, then consideration now needs to be given to a much more differentiated workforce and the importance of non-standard employment relations. ... Not only is standard work being replaced by various forms of nonstandard work, but the voluntary and non-paid forms of work have gained importance." They go on to discuss full-time vs part-time employment, casual employment, temporary employment, own-account self employment, and multiple job holders.

Statistics New Zealand gathers data on some of these forms of non-standard work, but not all. The census provides data on part-time vs full-timework, self employment vs wage and salary work, people with more 
than one job, and those who carry out work without pay in family businesses and farms. However, data are not collected on casual work or temporary work.

The data on non-standard work from the past five censi reveal that even in 1981, one quarter of all New Zealand workers $(24 \%)$ were in non-standard work. This has increased steadily to the point where two out of every five workers $(39 \%)$ were recorded as being in non-standard work in 2001.

Figure 11 disaggregates the three components of nonstandard work for which statistics are collected.

\section{Figure 11: Trends in Non-standard Work}

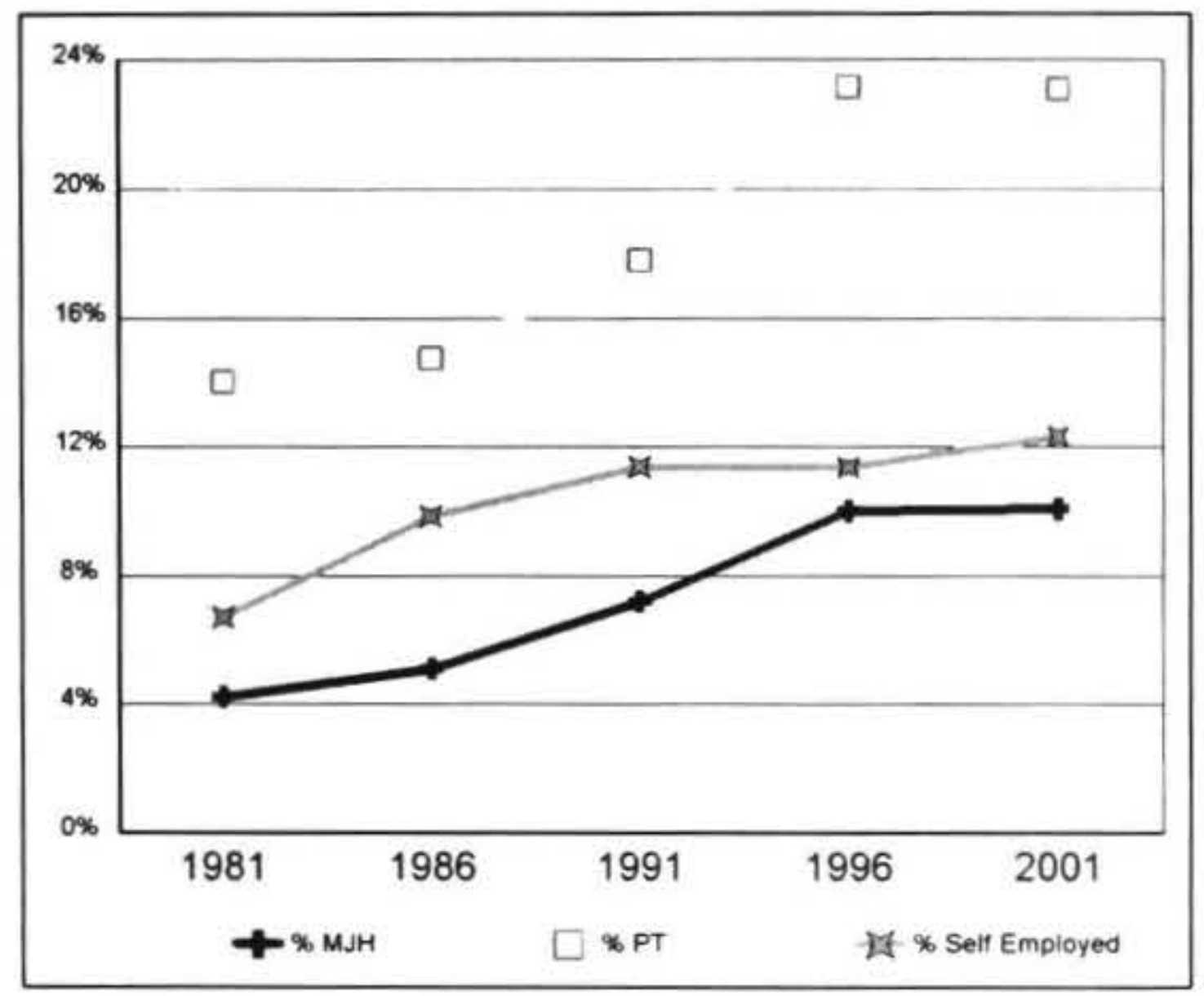

The move into non-standard forms of work was most rapid during the 1980 s and early 1990 s; the trend appears to have slowed in recent years, but the data show no signs of actual decline, at the aggregate, national level. This contrasts with trends reported by Mangan (2003, p3) from five out of seven selected countries. Mangan reported that aggregate rates of non-standard employment fell between 1997 and 2001 in Australia, USA, Sweden, Spain and the UK, but continued to rise in Japan and Germany.

\section{Long-term Trends in Multiple Job Holding}

The overall incidence of multiple job holding had not peaked in the New Zealand labour market at the time of the last census in 2001, although the rate of growth overall had certainly declined markedly since 1996 from that experienced during the preceding decade. In 2001, according to census data, 174,000 New Zealanders were recorded as being MJHers.

The census data sets provide an excellent basis on which to disaggregate this overall trend, the results of which are shown below by employment status, age band, sex, ethnicity and industry sector.

When disaggregated by employment status, the only group to exhibit declining rates of multiple job holding since 1996 are wage and salary earners. Whilst wage and salary earners are undoubtedly the single largest
Figure 12: MJH Trends - by Employment Status in the First Job

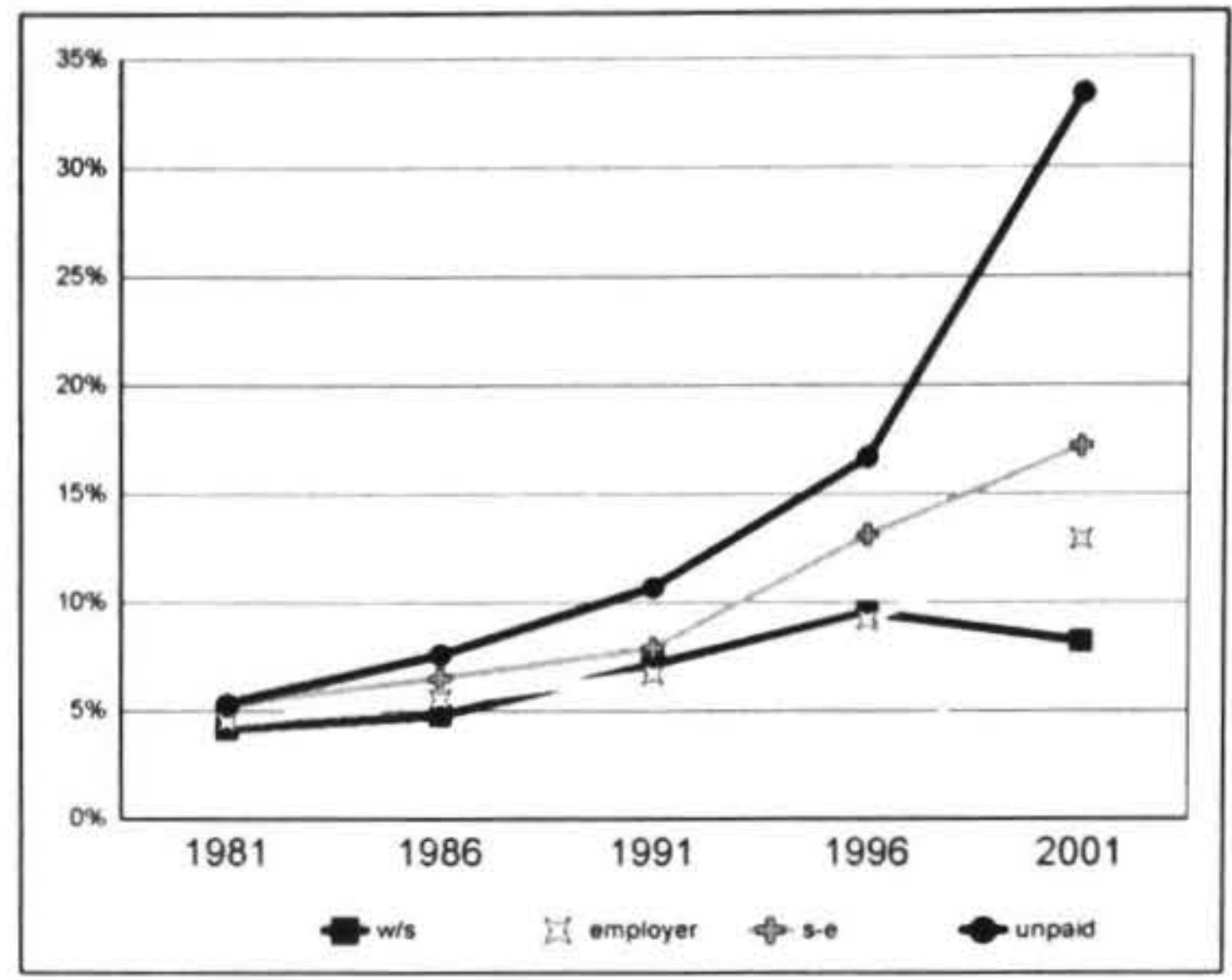

workforce group, their level of predominance has declined somewhat from $81 \%$ in 1986 to $75 \%$ in 2001 . For all other categories of employment status it is evident that rates of multiple job holding are still increasing markedly.

In 1981, there were almost twice as many male MJHers $(38,000)$ as female $(20,800)$. A decade later and women $(51,100)$ outnumbered men in the MJHer ranks. However latterly, MJH rates appear to have peaked for women while they are still increasing for men.

Figure 14 reveals some distinct differences in ethnic disposition to multiple job holding. Not only are the absolute rates substantially different, only NZ European and Asian workers are maintaining their rates of $\mathrm{MJH}$ involvement since 1996.

The pattern shown in Figure 15 raises an interesting question when thinking about future trends. The trends in $\mathrm{MJH}$ rate for age bands appear to distinguish younger workers from older workers. MJH rates for people aged 50-64 yrs and people aged 65 yrs and over show continuing strong growth since 1996, while those for all younger age bands show decline. One question that needs investigation is whether the higher rates in the older age bands will translate into continuing increase in the national $\mathrm{MJH}$ rate as the working population ages on a transient or permanent basis. Are the higher $\mathrm{MJH}$ rates for older age groups a reflection of a cohort of MJHers moving through the working population, or are there greater incentives, needs or opportunities for older workers to adopt this form of non-standard work?

Figure 16 reveals that $\mathrm{MJH}$ trends also vary markedly by industrial sector. The rurally-based primary industry sector continues to exhibit rapid growth in multiple job holding, while three other sectors (financial services, mining and electric utilities) also exhibited increasing MJH rates since 1996. However, MJH rates in manufacturing, construction and transport have levelled off, and $\mathrm{MJH}$ rates in wholesale \& trade and community services were declining by 2001 . 
Figure 13: MJH Trends - by Sex

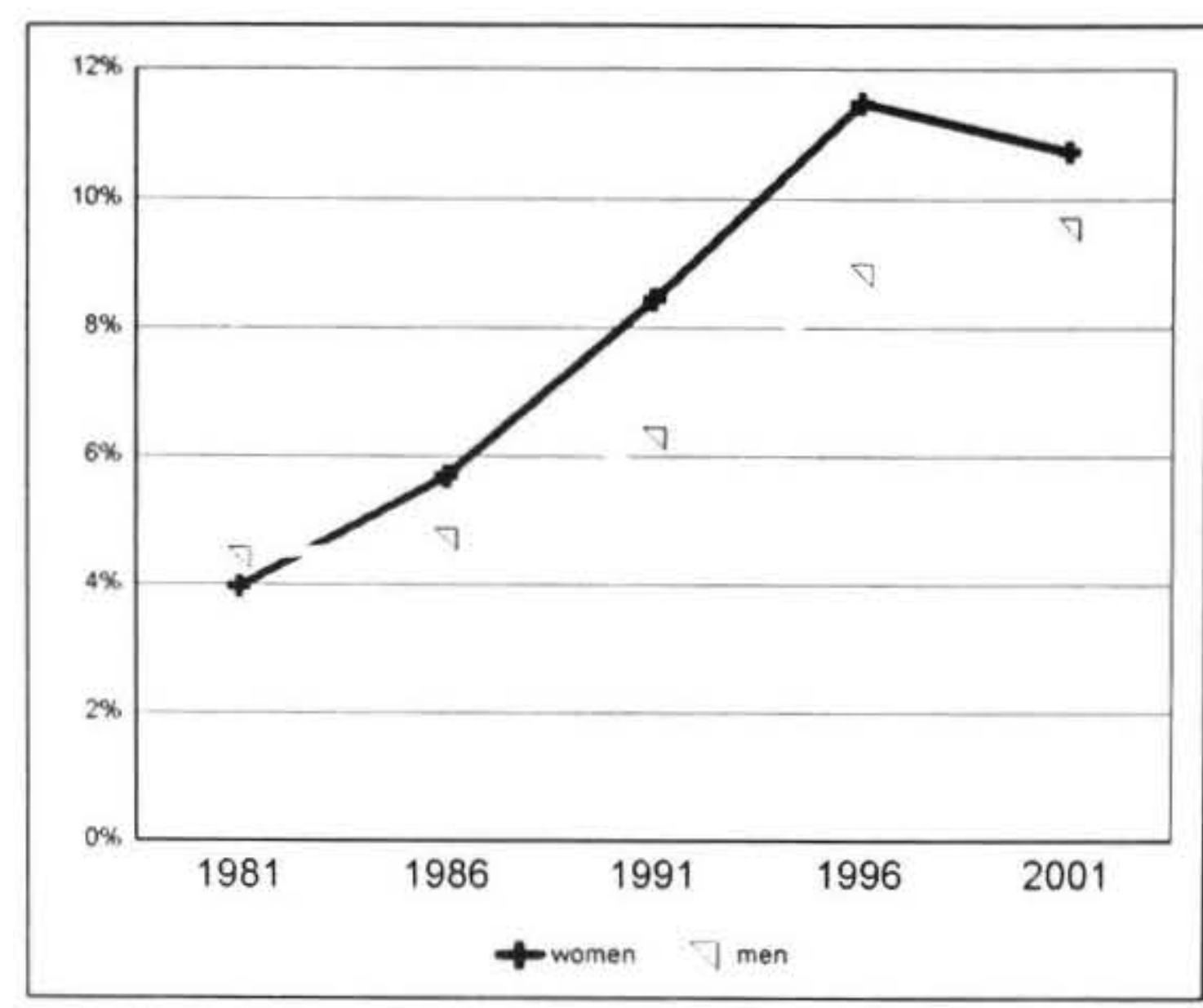

Figure 14: MJH Trends - by Ethnicity

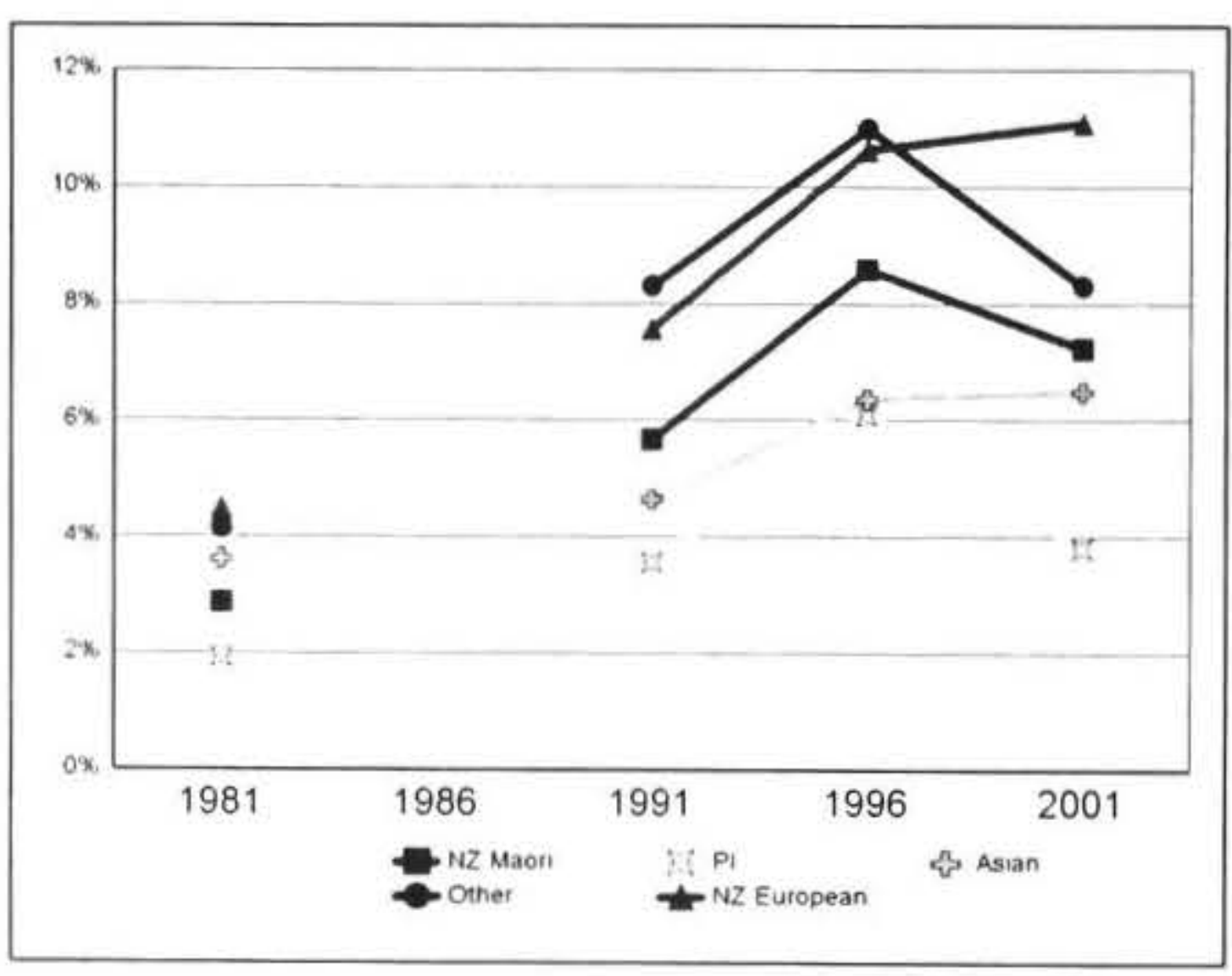

Figure 15: MJH Trends - by Age Band

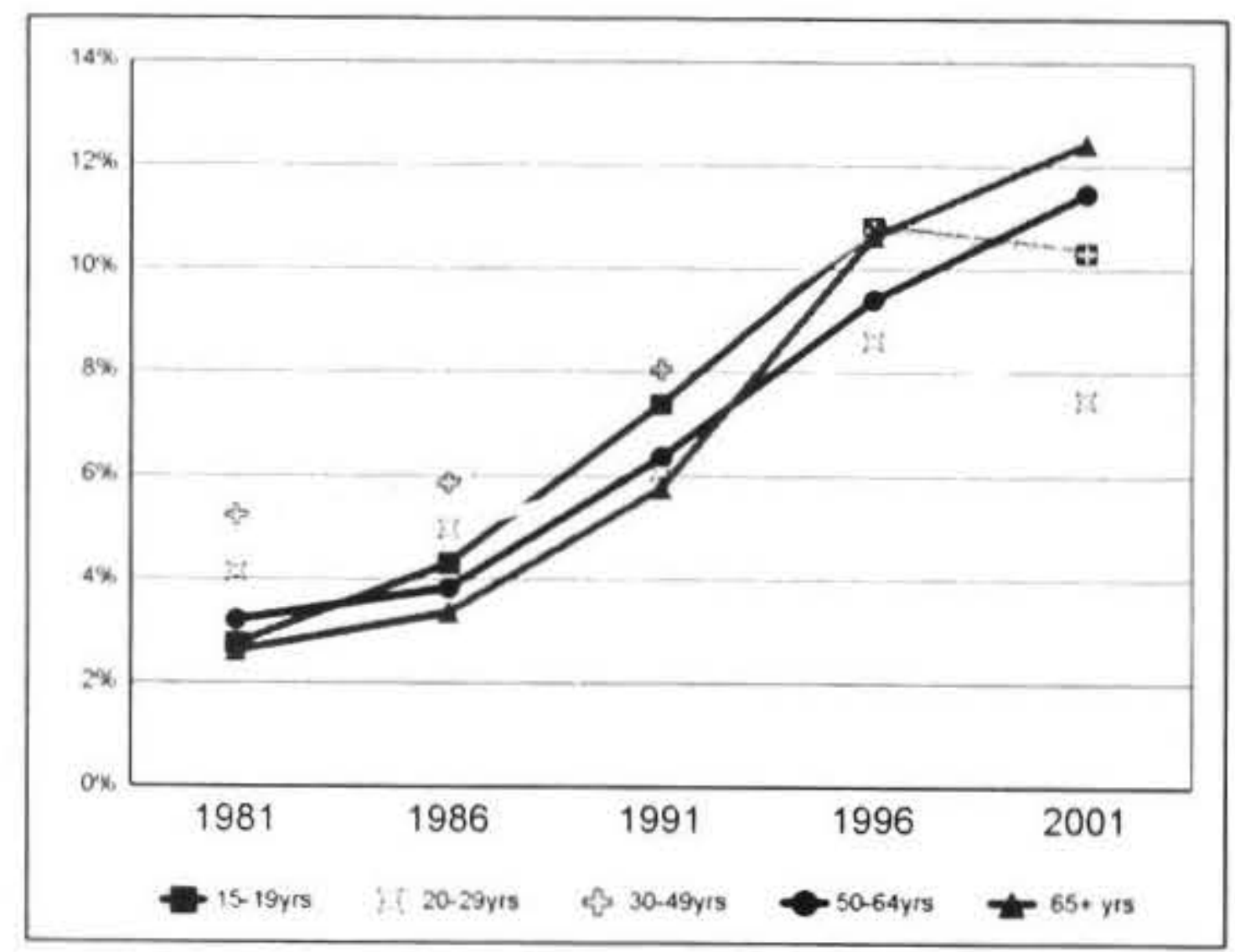

Within the Financial and Other Services sector there is some variation in recent trends; the Retail industry continues to exhibit increasing MJH rates, while rates in Business Services have levelled off and are declining in the Banking and Insurance industries.
Figure 16: MJH Trends - by Industry Sector

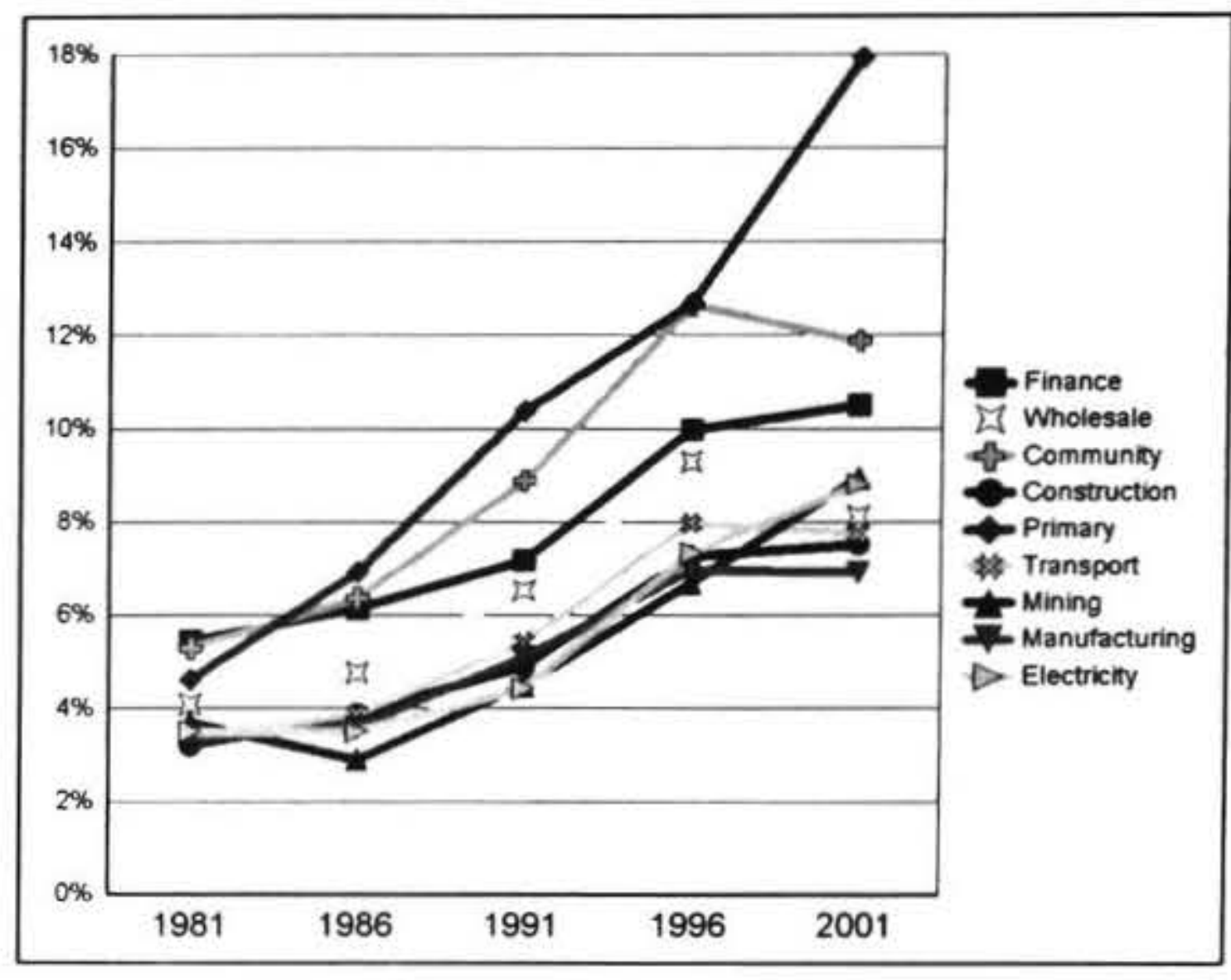

$\mathrm{MJH}$ rates for all industries in the Wholesale and Retail trade sector declined since 1996, but there was considerable variation amongst industries covered by the Community, Social and Personal Services sector. For example, MJH rates for Cultural Services, Research and Scientific Institutes, and Local Government Administration continued to increase, while rates for Social and Related Community Services levelled off and rates for most other industries declined.

In the Primary Industries sector, MJH rates were still increasing in 2001 in all industries except the racing Industry. Indeed, in a number of industries - beef farming, dairy farming and cropping in particular, MJH rates increased very substantially between 1996 and 2001.

In the Manufacturing Industries sector only two exhibited increasing MJH rates between 1996 and 2001 - the manufacture of concrete, clay and glass products, and the manufacture of fabricated metal products. MJH rates in all other manufacturing industries either levelled off or declined.

\section{Multiple Job Holding Data from the Time Use Survey}

The Time Use Survey (TUS) was carried out between July 1998 and June 1999 by Statistics NZ on behalf of the Ministry of Womens Affairs. It provides a one-off snapshot of how 8,500 New Zealanders typically spend their time both in work and in other community, household and personal activities. It is of particular interest in the context of this research programme because it is the only statistical survey which has gone into any detail about the nature of people's second and third jobs. It also provides an alternative benchmark for recent levels of multiple job holding.

Results from the TUS indicate that, in 1998/99, $11.6 \%$ of all workers had two jobs and a further $1.5 \%$ had three or more jobs, making a total of $13.1 \%$ of New Zealand 
workers who were MJHers at that time. This compares with the census-based estimates of $10.0 \%$ in 1996 and $10.1 \%$ in 2001 .

It is perhaps not surprising that the TUS indicated a higher level of MJHolding than the census. The TUS was an interviewer-administered survey which required respondents to think in more detail about the number and nature of their jobs. Both these factors (interviewer prompting and more specific questioning) would be likely to reduce the incidence where respondents either overlook second jobs or were not sure about whether to count a second job.

Nevertheless, it must be remembered that the margin for error is greater for a survey of 8,500 than it is for a complete national census, although this is unlikely to explain the observed difference completely (a sample size of 8,500 will result in a maximum sampling error of $\pm 1.4 \%$ at the $99 \%$ confidence level, which is 0.2 either side of the $13.1 \%$ figure).

The greatest advance in insight offered by the TUS is in terms of the data provided on occupations associated with each job. The census provides data on the occupation of the first job, although there is uncertainty as to whether or not these data properly reflect respondents' perceptions of what their main job is. The TUS provides data on the occupations of individuals in their various jobs. The analysis summarised below looks at the occupations of individuals in their first job and asks whether or not the occupation of their second job is the same or different; and similarly for their third job. Because of the limitations of sample size, this analysis has been done only at the one-digit (and partially at the two-digit) level of occupational classification. At the one-digit level of occupational classification, the results are as follows:

There is a very high level of cross-occupational multiple job holding, which implies that MJHers are applying somewhat different skill sets in there various jobs. In no occupational type is there a majority of MJHers who work in the same designated occupation for their first and second jobs.

\section{Discussion and Conclusions}

This research programme is nearing its midway point. Much of the statistical data that will be the subject of more detailed analysis has now been accessed and retrieved, although the first 20 -year census data sets have been available only in the past few months. There is still considerable work to be done in harmonising some of the census variables so that a broader range of 20 -year time series can be produced and studied.

A more exhaustive comparison of the various statistical data sets is necessary, and of the possible reasons for the scale of discrepancies, particularly between the census and the HLFS data sets. The degree of difference is so great as to suggest some systematic differences, such. Given the disproportionate degree of involvement of rural workers in multiple job holding, the question of sampling bias must be considered. The large differences in $\mathrm{MJH}$ rates between certain occupations begs the question of whether people in some occupations are more resistant to participating in the HLFS than others. To back simple logic and intuition, there is strong statistical evidence to show that people in more than one job tend to work much longer hours; this, in itself, might tend to make such people less accessible to inclusion in the HLFS.

The paper presented at the previous $10^{\text {th }} \mathrm{LEW}$ conference in 2002 (Baines et al. 2002) pointed to a number of reasons for suspecting that official statistics, particularly the HLFS and the census of households and dwellings, are likely to under-report the incidence of multiple job holding. A comparison of census $\mathrm{MJH}$ data with corresponding data from the Time Use Survey would seem to confirm this suspicion. Taking into account the special focus of the Time Use Survey, and the method of face-to-face interviewer administration of the survey, it is not surprising that the Time Use Survey reveals higher levels of multiple job holding. The Time Use Survey has also confirmed a high degree of cross-occupation multiple job holding, as a positive finding of its analysis. This would reinforce one of the major possible causes for under-reporting of multiple job holding in the selfadministered census; some respondents are either confused about what their main job is. Is importance attributed to the number of hours, the level of income, the significance for the household or even the association with personal identity - consider the individual who works in a bar to earn enough so that $s /$ he can be the semi-professional musician they see themselves as. In other cases, where one occupation is so different from the other - perhaps seen more as an interest or a hobby - the respondent simply forgets to report it.

The analysis presented here suggests that multiple job holding has definitely not peaked as a labour market phenomenon in New Zealand, although it may be close to doing so. Mangan (2003) postulates that, on the basis of the Australian experience of multiple job holding, it will not penetrate the labour markets to a much greater extent than is presently the case. Nevertheless, there were more occupational categories in the New Zealand labour market which displayed growth in rates of multiple job holding than showed declines in the last inter-censal period (19962001). Furthermore, some of these occupations say their MJH rates increase by more than $10 \%$ in absolute terms. The analysis presented in this paper points to the fact that while the overall trend to increasing adoption of multiple job holding has slowed, there are particular circumstances - or sets of circumstances - in which individuals are still likely to be considering more than one job - if they work in the rural sector, if they are self-employed or their first job is an unpaid one in the family business, if they work in the financial and business services sector, if they are in the latter part of their working life, and so on.

\section{Notes}

1. The research is funded by the Foundation for Research, Science and Technology, contract TBAX0204. 
2. Working in more than one job sequentially, as in a sequence of seasonal jobs, can also be viewed as a form of multiple job holding. However, in the context of this statistical analysis, the focus is specifically on those who work in more than one job at the same time.

3. A particular issue for analysing multiple job holding from official statistics is the high level of casual employment within the cash economy. Multiple job holders may be reluctant to report cash income from casual employment for reasons related to tax, child support and benefit receipts (Averett, 2001).

4. Estimates of maximum sampling error for the whole sample, at $99 \%$ confidence (i.e. 99 times out of 100).

5. Carried out in conjunction with the Ministry for Women's Affairs.

6. For example, in the $1980 \mathrm{~s}$, part-timework was not taken so seriously with the consequence that effort was not put into resolving data uncertainties; latterly, changes in data entry practice to computer scanning made this more difficult.

7. A major change in occupational classification systems occurred progressively between 1986 and 1996, moving from OCC068xx series to OCC090xx series.

8. The 1996 census changed the wording of the question and therefore the responses which people gave encouraging nomination of more than a single ethnicity.

9. For the first time in 1991, the personal questionnaire asked (Qu.22) 'Did you look for paid work in the last 4 weeks?' if the individual had answered 'No' to the question (Qu.21) 'Do you work in a job, business, farm or profession?' This allows a distinction (for the purposes of official statistics and policy analysis) within the ranks of those who described themselves as unemployed (not in work) between those who are actively seeking work and those who are not.

\section{References}

Averett, S. L. 2001, Moonlighting: multiple motives and gender differences, Applied Economics, 33(11), 1391.
Baines, J.T. \& Newell, J. 2003, A Profile of Multiple Job Holding in New Zealand based on 2001 census data, Working Paper No.2, Taylor Baines \& Associates, April 2003.

Baines, J.T., Newell, J. \& Taylor, C.N. 2002, Multiple Job Holding in New Zealand - a statistical profile, Paper presented at the $10^{\text {th }}$ LEW conference, Wellington, 21-22 November 2002.

Chapman, D. 2000, The rise and rise of the nonpermanent worker, Management August, 78-79.

Dept of Labour 2003, Work Trends: How work is changing in New Zealand, A Future of Work Programme report, Wellington, August 2003.

Hunt, R. 1996, The brave new flexible workplace world, People \& Performance, Sept., 7-12.

Mangan, J. 2003, Some aspects of Non-Standard Employment and Multiple Job holding in Australia, Paper presented to a workshop on Nonstandard work, 18 November 2003, Wellington.

McLaren, E. 2001, The growing insecurity of work, Working Paper No. 5, Labour Market Dynamics Research Programme, Massey University, Albany and Palmerston North.

Shirley, I., Firkin, P., Cremer, F., Dewe, P., Eichbaum, C., de Bruin, A., Dupuis, A. \& Spoonley, P. 2001, Transitions in the Hawkes Bay labour market: unpaid work and paid work, Research Report Series, Labour Market Dynamics Research Programme, Massey University, Albany and Palmerston North.

Spoonley, P. \& Davidson, C. 2004. 'The Changing World of Work', in Work \& Working in Twentyfirst Century New Zealand, eds P. Spoonley, A. Dupuis \& A. De Bruin, Dunmore Press, Palmerston North, pp.17-40.

Taylor, C.N. \& McCrostie Little, H. 1995, Means of survival? A study of off farm employment. Taylor Baines and Associates, Christchurch. 